\title{
On deglaciation-induced perturbations of the geoid
}

\author{
DETLEF WOLF \\ Department of Physics, The University of Toronto, Toronto, Ont., Canada M5S IA7 \\ Received May 29, 1985 \\ Revision accepted August 12, 1985
}

\begin{abstract}
The importance of geoid perturbations in interpreting tilts of glacial lake levels is investigated, using a representative theoretical model. It is shown that near the ice margin, the slope of the Earth's perturbed surface is everywhere large compared with the slope of the associated undulation of the geoid. Perturbations of the geoid may therefore be neglected in interpretations of glacial strandline tilt.
\end{abstract}

Un modèle théorique a été développé pour évaluer l'importance des perturbations du géoïde dans l'interprétation des relèvements des niveaux des lacs glaciaires. Il est démontré qu'à la marge des glaces, l'inclinaison de la surface perturtée de la Terre est en tous lieux considérable par rapport à l'inclinaison ondulée associée au géoïde. Par conséquent les perturbations du géoïde peuvent être omises dans les interprétations des relèvements des lignes de rivage des lacs glaciaires.

Can. J. Earth Sci 23, 269-272 (1986)

[Traduit par la revue]

\section{Introduction}

Recently, a reinterpretation of the strandline tilt associated with proglacial Lake Algonquin in North America in terms of lithospheric thickness was proposed (Wolf 1985). The employed model allowed for $(a)$ the finite rate of retreat of the Laurentide ice sheet and $(b)$ the viscous relaxation of the Earth's mantle. The results demonstrated that the value inferred for the thickness of the lithosphere is very sensitive to the cross section adopted for the ice sheet. For reasonable cross sections, thicknesses of $85-110 \mathrm{~km}$ were shown to be compatible with the tilt data; this is smaller by about a factor of two than an independent thickness estimate based on postglacial sea-level variations on the North American east coast (Peltier 1984).

A simplification of the analysis in Wolf (1985) was the neglect of deglaciation-induced geoid perturbations, although

\footnotetext{
'Present address: Division of Gravity, Geothermics and Geodynamics, Earth Physics Branch, Energy, Mines and Resources Canada, Ottawa, Ont., Canada KIA 0Y3.
}

the expected modifications were discussed qualitatively. In view of the differing estimates of lithospheric thickness, it appears to be in order, however, to investigate this particular feature more closely. This is done in the present note, which discusses glacial geoid perturbations on the basis of a representative quantitative model.

The controversy about the magnitude of the perturbation of the Earth's surface produced by Pleistocene ice masses compared with the magnitude of the accompanying geoid perturbation dates back to the nineteenth century. The issue was clearly formulated by Jamieson (1882), who reflected on the question whether "the centre of gravity of the earth be more likely to pull the cap down than the cap to shift the centre of gravity." Based on qualitative arguments, Jamieson concluded that the former effect is more significant than the latter.

In early quantitative investigations of glacial perturbations of the geoid, the Earth was usually considered to be rigid (e.g., von Drygalski 1887; Woodward 1888). One of the load models Woodward studied was a circular ice sheet of $38^{\circ}$ angular radius and approximately $3 \mathrm{~km}$ axial thickness, for 
which he calculated geoid slopes of the order of $0.1 \mathrm{~m} \mathrm{~km}^{-1}$ at points near the ice margin. Goldthwait (1908) noticed that this is much smaller than the tilts of the abandoned water planes of most glacial lakes in North America. He therefore concluded that "the inclined position of the planes . . . must be attributed to earth movements."

Later work included the finite strength of the Earth in the analysis of geoid perturbations. Initially, the Earth was modeled as an elastic sphere. The modifications introduced by the Earth's elasticity were summarized by Daly (1925).

More recently, the theory was generalized. In particular, geoid perturbations caused by $(a)$ redistribution of ocean water consequent upon melting of the ice and $(b)$ simultaneous viscous redistribution of mantle material were included and treated in a gravitationally self-consistent analysis (Farrell and Clark 1976; Clark et al. 1978; Peltier et al. 1978; Wu and Peltier 1983). These investigations showed that geoid perturbations are most important in interpreting relative sea level for sites far from glaciation centres and for times before deglaciation.

An interesting consequence of deglaciation-induced geoid changes for interpreting strandline emergence at sites close to glaciation centres is that the rise of sea level produced by the influx of melted ice is opposed by the simultaneous drop of the geoid caused by the disappearance of the ice mass (e.g., Clark 1976). This was demonstrated quantitatively for a site near the centre of the Laurentide ice sheet on the basis of realistic load and Earth models (Wu and Peltier 1983).

The influence of geoid perturbations on the interpretation of tilt data from glacial lakes is comparatively less well understood, although Woodward's (1888) results for a rigid Earth may serve as a crude guideline. In the following, a solution for the perturbation of the geoid associated with the loading of a viscoelastic Earth model will therefore be derived. This will allow us to show explicitly that in interpretations of tilts of glacial lake levels, the effect of geoid perturbations is small and may neglected.

\section{Theoretical model}

The theoretical Earth model chosen is the incompressible configuration described in Wolf $(1984,1985)$. It is composed of a uniformly viscous Maxwell mantle surrounded by a uniformly elastic lithosphere. The characteristic model parameters are listed in Table 1.

The solution for the radial surface deflection $u_{\mathrm{r}}$ for this model produced by a load $P_{n}$ may be written as (Wolf 1984)

[1] $u_{\varepsilon}=-T_{n}^{(\mathrm{ve})} P_{n}$

In this equation, $P_{n}$ denotes the Legendre polynomial of angular order $n$, and $T_{n}^{\text {(ve) }}$ is the viscoelastic transfer function for a Heavyside unloading event.

As the Earth is assumed to be incompressible, only load and surface deflection contribute to the density perturbation. In the linear approximation, both contributions can be represented by a surface density distribution $x$. The potential perturbation $\delta U$ is therefore a solution of Laplace's equation. If the usual boundary conditions for potential fields are observed, we find, for points at the Earth's surface,

[2] $\delta U=-4 \pi \gamma a \times P_{n} /(2 n+1)$

where $\gamma$ denotes the graviational constant, and $a$ is the Earth's radius. The surface density is given by
[3] $x=1 / g-\rho T_{n}^{(\mathrm{ve})}$

with $g$ the surface acceleration due to the gravity and $\rho$ the density of the Earth. The first term on the right-hand side of [3] is associated with the extemal load; the second term represents the contribution of the perturbed surface of the Earth model characterized by $T_{n}^{\text {(ve) }}$. It should be noted that the solutions for displacement and potential, [1] and [2], neglect the vicsoelastic-gravitational coupling. The theory is therefore similar to Farrell's (1972) analysis of gravitational effects caused by the deformation of a uniform, elastic half space.

For the following, it is necessary to determine the geoid deflection $\epsilon$ resulting from the potential perturbation $\delta U$. We find (e.g., Officer 1974, pp. 288-289)

[4] $\epsilon=\delta U / g$

\section{Numerical example and discussion}

In order to compare the deflection of the Earth's surface with the deflection of the geoid for a particular load, the solution must be transformed to the spatial domain. This only requires standard numerical operations, which were outlined previously (Wolf 1984). The following results apply to a load of parabolic cross section, $4 \mathrm{~km}$ axial thickness, $1600 \mathrm{~km}$ radius, and $1000 \mathrm{~kg} \mathrm{~m}^{-3}$ density acting during the time interval $-\infty<t<0$.

In Fig. 1a, the relaxation of the Earth's surface near the load margin at different times with respect to the time of load removal is shown. The difference in radial displacement between $t<0$ and $t=+0$ reflects the instantaneous elastic recovery at $t=0$. The inward movement of the zero crossing of the deflection curve with increasing time has been repeatedly discussed (e.g., Cathles 1975, pp. 184-191). The behaviour is generally considered to be indicative of a nearly uniform viscosity structure in the Earth's mantle.

Figure $1 b$ illustrates the accompanying geoid deflection. For the period of loading, $t<0$, we note that the influence of the elastic lithosphere is not strong enough to produce significant distortions of the geoid from sphericity. The almost uniform elevation of the geoid by approximately $20 \mathrm{~m}$ is a consequence of an increase in total mass by the mass of the load.

At $t=0$, the mass excess represented by the load is removed, whereas, except for elastic recovery, the mass deficit represented by the surface depression remains. The load removal causes an instantaneous drop of the geoid by $40-80 \mathrm{~m}$ near the load margin. The resulting geoid depression decays gradually until, at $t \rightarrow \infty$, gravitational equilibrium is restored. Of some interest is the observation that although the deflection of the geoid is significant in absolute terms, it is about one order of magnitude smaller than the radial deflection of the Earth's surface.

The predicted land uplift and the predicted geoid uplift in the time interval $t \geqq t_{0}$ are given by

[5] $H_{\mathrm{u}}(t)=u_{\mathrm{r}}(t)-u_{\mathrm{r}}\left(t_{0}\right)$

and

[6] $H_{\epsilon}(t)=\epsilon(t)-\epsilon\left(t_{0}\right)$

respectively. Figure 2 illustrates predicted uplift gradients, $\mathrm{d} H_{\mathrm{u}} / \mathrm{d} s$ and $\mathrm{d} H_{\epsilon} / \mathrm{d} s$, for a point at the ice margin. In Fig. $2 a$, $t_{0}=-0$ has been assumed; in other words, uplift since unloading is considered. After load removal the land-uplift gradi- 
TABLE 1. Parameters of Earth model

\begin{tabular}{ccccc}
\hline \hline & $\begin{array}{c}h \\
(\mathrm{~km})\end{array}$ & $\begin{array}{c}\rho \\
\left(\mathrm{kg} \mathrm{m}^{-3}\right)\end{array}$ & $\begin{array}{c}\mu \\
\left(\mathrm{N} \mathrm{m}^{-2}\right)\end{array}$ & $\begin{array}{c}\eta \\
(\mathrm{Pa} \mathrm{s})\end{array}$ \\
\hline 1 & 100 & 3320 & $0.67 \times 10^{11}$ & $\infty$ \\
2 & 6271 & 3320 & $1.45 \times 10^{11}$ & $1.0 \times 10^{21}$ \\
\hline
\end{tabular}
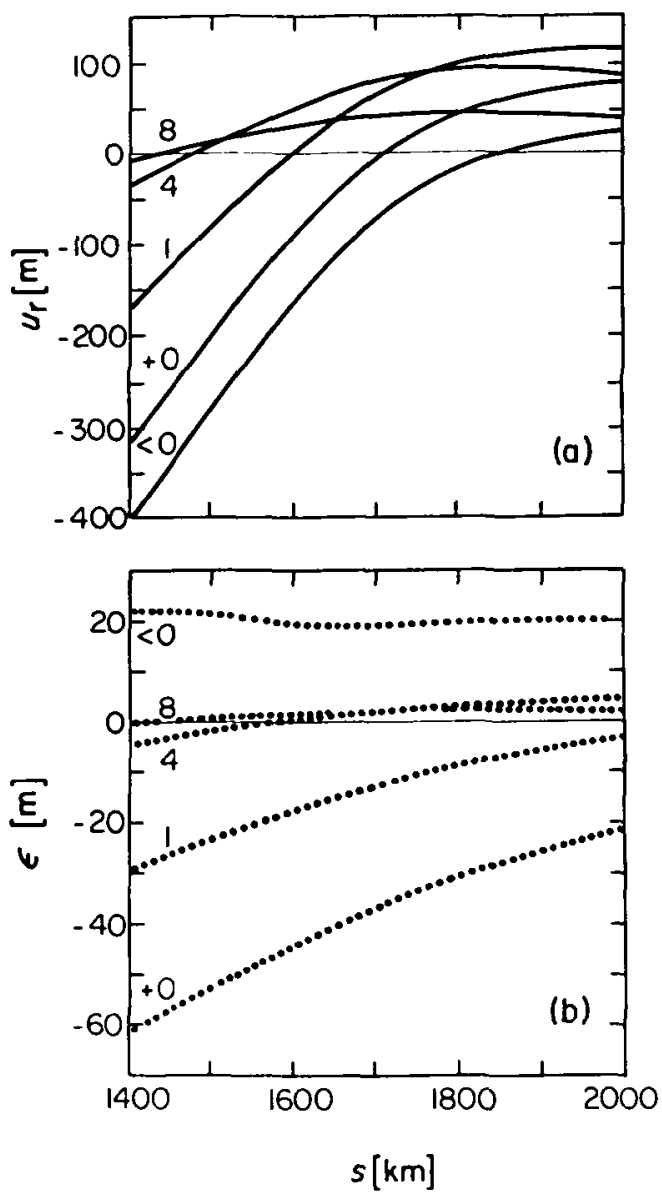

FiG. 1. (a) Surface displacement $u_{\mathrm{r}}$ and $(b)$ geoid displacement $\epsilon$ as functions of axial distance $s$ for several times (ka) with respect to time of load removal.

ent increases monotonically. This is also obvious from Fig. 1a. The magnitude of the geoid-uplift gradient remains very small in comparison. Its positive sign is a consequence of the fact that the reference surface is the spheroidal geoid existing during loading (Fig. 1b). In addition to predictions of uplift gradient, the observed range of strandline tilts associated with proglacial Lake Algonquin near its upwarped northem end (e.g., Walcott 1972) is shown as a hatched band.

Clearly, the deleveling of an ancient strandline reflects the warping of the solid surface and the warping of the geoid since time of strandline formation. Predicted strandline emergence is therefore given by $H=H_{u}-H_{\epsilon}$, and $\mathrm{d} H / \mathrm{d} s$ should be used for predictions of strandline tilt. From Fig. $2 a$ it is, however, apparent that $\left|\mathrm{d} H_{\epsilon} / \mathrm{d} s\right| \ll\left|\mathrm{d} H_{\mathrm{u}} / \mathrm{d} s\right|$, so that $\mathrm{d} H / \mathrm{d} s \equiv \mathrm{d} H_{\mathrm{u}} / \mathrm{d} s$. We may therefore employ the land-uplift gradient for predictions of strandline tilt. This is the approximation used previously (Walcott 1970; Wolf 1985). As


Fig. 2. Predictions of land-uplift gradient $\mathrm{d} H_{\mathrm{u}} / \mathrm{d} s$ (solid) and geoiduplift gradient $\mathrm{d} H_{\epsilon} / \mathrm{d} s$ (dotted) at axial distance $s=1600 \mathrm{~km}$ for uplift since $(a) t_{0}=-0$ or $(b) t_{0}=6 \mathrm{ka}$ as functions of time $t$; crosshatched band indicates range of observed strandline tilts $\mathrm{d} H / \mathrm{ds}$ for $(a)$ proglacial Lake Algonquin or $(b)$ postglacial Lake Nipissing; times are with respect to time of load removal.

shown, the land-uplift gradient matches the observed strandline tilt associated with proglacial Lake Algonquin at approximately $12 \mathrm{ka}$ after load removal, that is, today.

If uplift is measured with respect to a time after the unloading event, the sign of the geoid-uplift gradient must change. This is obvious from Fig. $1 b$ and explicitly shown in Fig. $2 b$, where $t_{0}=6 \mathrm{ka}$ has been assumed. As before, $\mathrm{d} H / \mathrm{d} s \cong \mathrm{d} H_{\mathrm{u}} / \mathrm{d} s$, and tilt predictions reach values comparable to the maximum strandline tilts associated with postglacial Lake Nipissing in North America (e.g., Walcott 1972) at about $12 \mathrm{ka}$ after unloading. As the age of Lake Nipissing is not more than 6 ka (e.g., Prest 1970), the agreement is satisfactory in view of the simple unloading event employed.

\section{Conclusion}

This study has demonstrated that geoid perturbations are of minor importance in interpreting proglacial or postglacial lake tilts. The corrections are, in particular, small compared with the accuracy of the tilt data. Previous suggestions to include the effect of geoid perturbations in tilt interpretations (e.g., Clark 1980; Wolf 1985) are therefore unfounded, and the ne- 
glect of this feature by Walcott (1970) and Wolf (1985) in their studies of the deleveling of proglacial Lake Algonquin appears to be justified.

This is certainly a useful result in its own right. Unfortunately, it fails to illuminate the mutual relationship between the estimates of about $100 \mathrm{~km}$ on one side (Walcott 1970; Wolf 1985 ) and the estimate of about $200 \mathrm{~km}$ on the other (Peltier 1984) for the thickness of the North American lithosphere. As the assumption of pronounced lateral inhomogeneity is unreasonable, the difference in thicknesses is likely to be apparent. The thickness estimates must therefore be looked upon with some reservation at present.

\section{Acknowledgment}

This investigation was financially supported by a Natural Sciences and Engineering Research Council of Canada postdoctoral fellowship.

Cathles, L. M. 1975. The viscosity of the Earth's mantle. Princeton University Press, Princeton, NJ.

Clark, J. A. 1976. Greenland's rapid postglacial emergence: a result of ice-water gravitational attraction. Geology, 4, pp. 310-312.

1980. The reconstruction of the Laurentide ice sheet of North America from sea level data: method and preliminary results. Joumal of Geophysical Research, 85, pp. 4307-4323.

Clark, J. A., Farrell, W. E., and Peltier, W. R. 1978. Global changes in postglacial sea level: a numerical calculation. Quaternary Research, 9, pp. 265-287.

DALY, R. A. 1925. Pleistocene changes of level. American Joumal of Science, Series 5, 10, pp. $281-313$.

Drygalski, E. von. 1887. Die Geoiddeformationen der Eiszeit. Zeitschrift der Gesellschaft für Endkunde zu Berlin, 22, pp. 169-280.

FARRELL, W. E. 1972. Deformation of the Earth by surface loads.
Reviews of Geophysics and Space Physics, 10, pp. 761-797.

Farrell, W. E., and Clark, J. A. 1976. On postglacial sea level. Geophysical Joumal of the Royal Astronomical Society, 46, pp. 647-667.

GoldthWAIT, J. W. 1908. A reconstnuction of water planes of the extinct glacial lakes in the Lake Michigan basin. Joumal of Geology, 16, pp. 459-476.

Jamieson, T. F. 1882. On the cause of the depression and reelevation of the land during the glacial period. Geological Magazine, 9, pp. 400-407.

OFFICER, C. B. 1974. Introduction to theoretical geophysics. Springer-Verlag, Berlin, FRG.

Peltier, W. R. 1984. The thickness of the continental lithosphere. Joumal of Geophysical Research, 89, Pp. 11303 - 11316.

Peltier, W. R., Farrell, W. E., and Clark, J. A. 1978. Glacial isostasy and relative sea level: a global finite element model. Tectonophysics, 50, pp. $81-110$.

Prest, V. K. 1970. Quaternary geology. In Geology and economic minerals of Canada. 5th ed. Edited by R. J. W. Douglas. Geological Survey of Canada, Economic Geology Report 1, pp. 675-764.

WALCOTT, R. I. 1970. Isostatic response to loading of the crust in Canada. Canadian Joumal of Earth Sciences, 7, pp. 716-727.

1972. Late Quaternary vertical movements in eastem North America: quantitative evidence of glacio-isostatic rebound. Reviews of Geophysics and Space Physics, 10, pp. 849-884.

WoLf, D. 1984. The relaxation of spherical and flat Maxwell Earth models and effects due to the presence of the lithosphere. Joumal of Geophysics, 56, pp. 24-33.

- 1985. An improved estimate of lithospheric thickness based on a reinterpretation of tilt data from Pleistocene Lake Algonquin. Canadian Joumal of Earth Sciences, 22, pp. 768-773.

WOODWARD, R. S. 1888 . On the form and position of the sea level. Bulletin 8 of the United States Geological Survey, pp. 87-172.

Wu, P., and Peltier, W. R. 1983. Glacial isostatic adjustment and the free air gravity anomaly as a constraint on deep mantle viscosity. Geophysical Joumal of the Royal Astronomical Society, 74, pp. $377-449$. 